\title{
THE EFFECTS OF SCOPOLAMINE HYDROBROMIDE ON ONE-WAY AND TWO-WAY AVOIDANCE LEARNING IN RATS*
}

\author{
EVAN SUITS and Robert L. ISAACSON \\ University of Michigan, Ann Arbor, Mich., U.S.A.
}

(Accepted 2 February 1968)

\begin{abstract}
Summary-Previous studies have shown certain striking similarities between the behavioral effects produced by some anticholinergic drugs and the effects produced by hippocampal destruction. To investigate this parallel more thoroughly, scopolamine hydrobromide was administered to rats in one-way and two-way active avoidance learning situations. The drugged animals showed improved learning of the two-way problem, reaching criterion in one-half the number of trials and making one-third as many errors as the saline injected controls. In the one-way task the drugged subjects performed slightly worse than control animals. These data correspond very closely to those from similar experiments using hippocampectomized subjects.
\end{abstract}

\section{INTRODUCTION}

RECENT research has shown that some anticholinergic drugs produce marked changes in learning and performance of certain tasks. Certain behavioral changes produced by the drugs scopolamine and atropine show a striking similarity to effects produced by bilateral removal of the hippocampus. RoBerTs et al. (1962) and Douglas and ISAACSON (1964) reported a reduction in the tendency to alternate responses in an exploratory situation in which no response is rewarded (spontaneous alternation) on the part of animals with hippocampal destruction. These same studies indicated that these animals continued to explore novel situations longer than either intact animals or animals with only neocortical destruction. Douglas and IsaACson (1966) found a similar reduction in spontaneous alternation in rats injected with scopolamine, while CARLTON (1965) found prolonged exploration in novel situations with the same drug. Many studies have found that rats with hippocampal lesions tend to perseverate inappropriate patterns of responding (e.g. KIMBLE and KIMBLE, 1965). HEARST (1959) has shown that scopolamine also increased perseveration of inappropriate responses in a double-discrimination problem. Clark and IsaAcson (1965) found that hippocampal lesions produced deficits in behavior on an operant schedule in which animals must wait at least 20 seconds between bar presses in order to be rewarded, a premature response voiding the reward and recycling the timer. CARLTON (1963) found similar results with animals under the influence of atropine. KImBle (1963) found hippocampal ablation to disrupt learning in a successive brightness discrimination problem, while WHITEHOUSE (1964) found the same effect due to atropine.

*This investigation was supported in part by a grant from the National Institute of Mental Health (NIH MH-1 12-8502) to R. L. Isaacson. 
The purpose of this experiment was to test more extensively for parallel effects between scopolamine and hippocampal destruction. ISAACSON et al. (1961) found that hippocampal lesions facilitate learning of a two-way avoidance (shuttle-box) task while, in a similar experiment, OLTON and ISAACSON (1966) found the same results in a two-way task, but, in addition, found subjects with hippocampal lesions somewhat worse than controls in acquiring a one-way active avoidance task.

Because hippocampal destruction leads to both improved performance in the case of one of these problems, the two-way problem, and impaired performance in the case of the other, the one-way task, we felt that this presented an unusual opportunity to test for possible similarity of effects of scopolamine and hippocampal destruction since both improved and impaired performance levels in apparently similar tasks could be predicted.

\section{METHOD}

Subjects (Ss) were 24 adult male albino rats approximately $80-90$ days old and weighing $300-350 \mathrm{~g}$ at the beginning of the experiment. All animals were individually housed and given food and water ad libitum, throughout training.

Training was done in a two-compartment shuttle box $17 \times 7 \times 12 \mathrm{in}$. with a grid floor. The two compartments were separated by a $3 \mathrm{in}$. high barrier and an opaque, vertically sliding door which was raised and lowered by the experimenter. A $5 \times 9$ in. white card was mounted at the end of the right-hand compartment and a black card was placed at the end of the left-hand compartment to enhance discrimination between the two sides. Compartments were individually illuminated by a $6 \mathrm{~W}$ bulb in each side. The front panel of the box was glass, allowing observation of $S$, and could be raised and lowered for placement and replacement of $S$ in the appropriate compartment. Electric shock could be delivered to either side of the shuttle box to S's feet through the grid. The shock source was a Grason Stadler Shock Generator with a supplementary device for "locking out" the generator for the first $10 \mathrm{sec}$ after the door between the compartment was raised, thus preventing accidental shock pulses in the period between the CS and US. Alternation of the grid to which shock was delivered and of the illumination of the pertinent compartment was controlled by a double-throw toggle switch. Besides the light and the raising of the door, the onset of a trial was signalled by a buzzer which remained on as long as the door was raised. Response latencies were timed with a standard stop clock.

Ss were divided into four equal groups $(\mathrm{N}=6)$ to provide control and experimental groups for the one-way and two-way avoidance learning tasks. To control for possible enhancement of drug effects due to successive applications, all groups were run every other day, allowing 48 hours between injections, Ss to be run on a given day were weighed, injected, and returned to their home cages $30 \mathrm{~min}$ before training. Injections for experimental group Ss were made i.p. using scopolamine hydrobromide $(0.4 \mathrm{mg} / \mathrm{ml} \mathrm{USP})$ at a dosage level of $1.0 \mathrm{mg} / \mathrm{kg}$, which has been demonstrated to produce behavioral effects similar to those of hippocampal destruction in the studies cited above. Control groups Ss were similarly injected with an equivalent amount of isotonic saline solution.

Ss were trained in the one-way task by placing them in the right-hand compartment with the light on. After $30 \mathrm{sec}$ the dividing door was raised, thus activating the buzzer and starting the 10 sec CS-US interval. Simultaneously with the raising of the door, the light was turned off in the initial compartment and turned on in the second compartment. After 10 
sec, $0.5 \mathrm{sec}$ pulses of $0.8 \mathrm{~mA}$ shock were delivered $1 / \mathrm{sec}$ until Ss hind feet had passed over the barrier. The door was then lowered and the latency recorded. After about $10 \mathrm{sec}$ in the left compartment, $\mathrm{S}$ was removed by hand and replaced in the right side.

Ss in the two-way task were trained to run in both directions and hence were not handled during a day's running. Otherwise, training for the two tasks was the same. Ss always ran from a darkened compartment into a lighted one. A $30 \mathrm{sec}$ inter-trial interval was maintained throughout training for both tasks.

An avoidance response was counted if $\mathrm{S}$ crossed the barrier before the 10-sec CS-US interval elapsed. Ss were given 20 trials per training day until a criterion of 19 correct responses out of 20 trials was reached.

\section{RESULTS}

Comparisons were performed utilizing (1) number of trials to the first correct response, (2) number of trials to a performance level of 9 avoidances in 20 trials, (3) number of errors to a performance level of 9 avoidances in 20 trials, (4) the number of trials to a performance level of 19 avoidances in 20 trials, and (5) number of errors to a performance level of 19 avoidances in 20 trials (cf. Table 1).

In addition, successive criteria curves, patterned after those developed by Horel et al. (1966), were prepared for all four groups. For each group of Ss, performance levels, in terms of number of avoidance responses in 20 trials, were plotted against the number of the last trial in the block of 20 in which the performance level was reached. The curves shown in Fig. 1 represent group means for this measure. Using this method, perfect performance from the first trial is represented by a straight line starting at zero and reaching the 19 out of 20 performance levels at trial 19 . Straight lines with the same slope as the reference line indicate maximally rapid progression to successively higher response rates. Errors which occurred before the first avoidance response displace the point of origin of these curves.

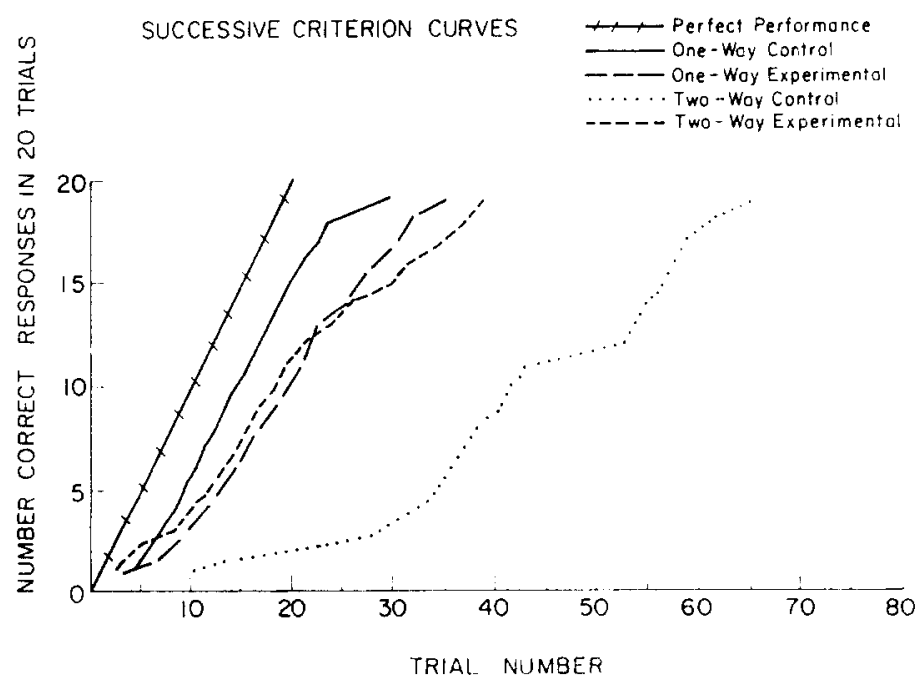

FIr, 1. Successive criterion curves showing acquisition rates of all groups, and reference line indicating perfect performance. See text for further details. 
Errors made after the initial avoidance response tend to reduce the slope of the curves. Therefore, the closer a curve approached the $\mathrm{x}$-axis the slower the progression through the performance levels due to more frequent errors.

Comparisons of group means are presented in Table 1. In the one-way task, the group of animals receiving scopolamine was found to be inferior to the normal Ss, and $t$-tests indicate a significant difference in mean number of both trials and errors to a performance level of 9 avoidance responses in 20 trials, but no differences were found between the groups" mean number of either trials or errors to a 19 avoidance responses in 20 trials criterion. Also, the differences in the number of trials to the first avoidance response was not significant. This indicates, as do the curves on Fig. 1, that the animals which received scopolamine made more errors in early training but performed as well as controls in the later stages of acquisition.

In the two-way task, the experimental group performance was superior to the control group. Significant differences in group means for all measures were found, except the number of trials to first avoidance response ( $t$-test). The experimental group required one-half as many trials and committed less than one-third as many errors as the control group in reaching the final criterion. Figure $I$ shows that although the two groups began making avoidance responses at the same time, the experimental group animals learned the two-way task almost as fast as the one-way task. In the two-way problem, the control group made much slower progression through successive performance levels at all stages of training.

Subjects in the one-way control group progressed almost as rapidly as possible through successively more difficult performance levels, once a few avoidance responses were made. The experimental groups in both tasks began avoidance responding as early as Ss in the control groups but did not advance at this maximum rate, making a moderate number of errors. On the other hand, control Ss in the two-way task advanced through the more difficult performance criteria very slowly, making many errors.

\section{DISCUSSION}

The data from the drugged animals in two-way active avoidance task correspond closely to those obtained by ISAACSON et al. (1961) and OLTON and ISAACSON (1966), and suggest that the effects of scopolamine are similar to those produced by large hippocampal lesions. In terms of magnitude, the performance of the drugged Ss is slightly worse than that of the controls in the one-way task, it is greatly superior to control Ss in the two-way task. While many experimental manipulations may act to produce decrements in learning or performance, the administration of scopolamine has, in this case, produced a decrement in the learning of one task and facilitation of learning of another similar task using the same shock level, apparatus and experimental environment as well as the same experimenter. This same facilitation and reversal of effect has been seen in hippocampectomized Ss and thus the similarity of the results of the two treatments is more firmly established.

Moreover, the results of this experiment are not readily explicable in terms of a general interference with memory, since the same procedures and motivational stimuli were involved. For the same reasons, the results obtained from animals with hippocampal lesions suggest that an overall memory impairment hypothesis is inadequate to account for the data. The changes produced by the drug and by the lesion appear to affect differentially other variables mediating performance in the two avoidance tasks. Determination of these variables is, of course, essential and hinges upon an evaluation of the behavior requirements of the two problems. 


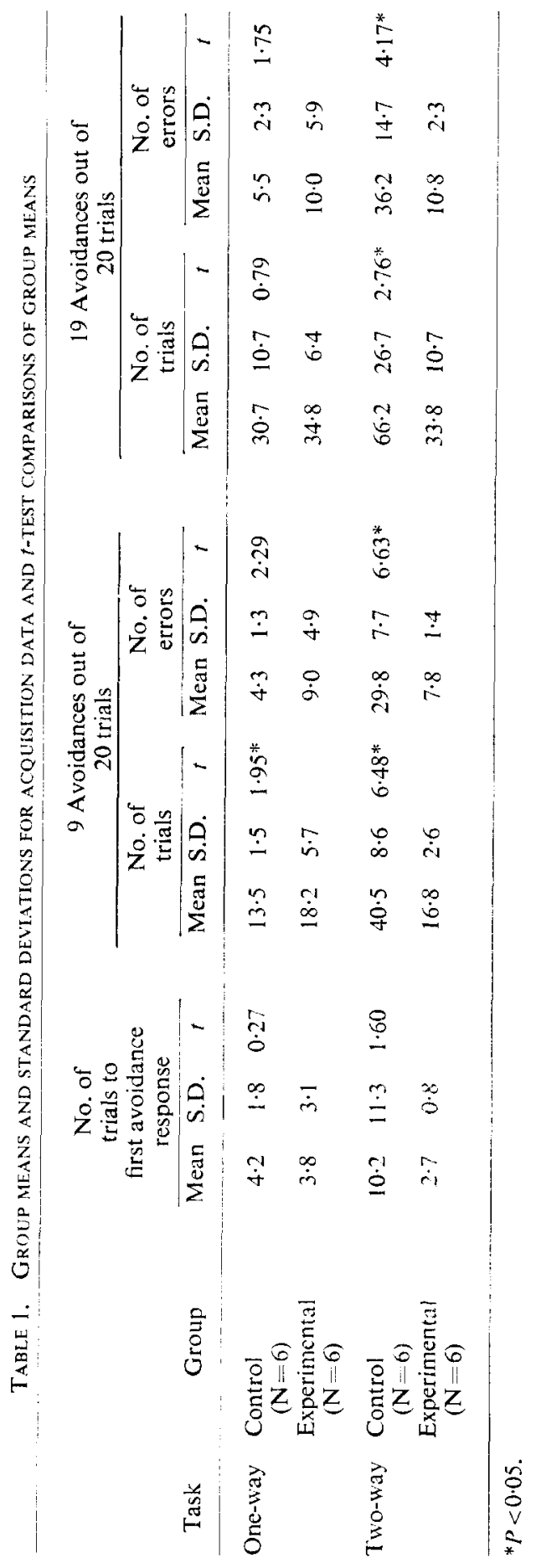


The differences between the tasks which may account for the differential drug effects include handling, the presence of a consistently safe compartment in the one-way but not in the two-way problem, and possible other features as well. However, OLton and ISAACSON (1968, in press) have shown that handling, per se, cannot account for the differences between the problems.

The presence of a uniformly safe place in the one-way task may lessen the conflict, concomitant with the two-way task, of returning to a place in which shock has been received on earlier trials. Similarly, less emotionality may be induced by the one-way task, because of the availability of a uniformly safe compartment in this case.

Whether differences in emotionality of the animals as they learn the two problems or some other training factor is vital to both the lesion and drug effects remains to be discovered.

\section{REFERENCES}

Carlton, P. L. (1963). Cholinergic mechanisms in the control of behavior by the brain. Psychol. Rev. 70: $19-39$.

Carlton P. L. (1965). The hippocampus, brain-acetylcholine, and habituation. Paper presented at Symposium on Brain, Biochemistry and Behavior: American Association for the Advancement of Science Meetings, Berkeley, California.

CLARK, C. V. H. and IsAACSON, R. L. (1965). Effect of bilateral hippocampal ablation on DRL performance. J. Comp. Physiol. Psychol. 59: 137-140.

DOUGlas, R. J. and ISAACSON, R. L. (1964). Hippocampal lesions and activity, Psychon. Sci. 1: 187-188.

Douglas, R. J. and IsAacson, R. L. (1966). Spontaneous alternation and scopolamine. Psychon. Sci. 4: 283-284.

HeARST, E. (1959). Effects of scopolamine on discriminated responding in the rat. J. Pharmac. Exp. Therap. 126: $349-358$.

Horel, J. A., Bettinger, L. A., Royce, G. D. and Meyer, D. R. (1966). Role of neocortex in the learning and relearning of two visual habits by the rat. J. Comp. Physiol. Psychol. 61: 66-78.

IsaAcson, R. L. Douglas, R. J. and MoORe, R. Y. (1961). The effect of radical hippocampal ablation on acquisition of avoidance response. J. Comp. Physiol. Psychol. 54: 625-628.

Kimble, D. P. (1963). The effects of bilateral hippocampal lesions in rats. J. Comp. Phisiol. Psychol. 56: 273-283.

Kimble, D. P. and Kimble, R. J. (1965). Hippocampectomy and response perseveration in the rat. J. Comp. Physiol. Psychol. 60: 474-486.

Olton, D. S. and IsaAcson, R. L. (March 5, 1966). The effect of hippocampal lesions upon acquisition of one-way and two-way active avoidance. Paper presented at Midwestern Psychological Association, Chicago.

OLton, D. S. and IsAacson, R. L. (In press). The importance of spatial location in active avoidance tasks. J. Comp. Physiol. Psychol.

Roberts, W. W., Dember, W. N. and Brodwick, M. (1962). Alternation and exploration in rats with hippocampal lesions. J. Comp. Physiol. Phychol. 55: 695-700.

Whttehouse, J. M. (1964). Effects of atropine on discrimination learning in the rat. J. Comp. Phisiol. Psychol. 57: 13-15. 